\title{
Conversão e balanço de energia de sistemas de produção com integração lavoura-pecuária sob plantio direto
}

\author{
Henrique Pereira dos Santos ${ }^{(1)}$, Renato Serena Fontaneli(1), Silvio Tulio Spera( ${ }^{(2)}$ e Geórgia Luiza Maldaner ${ }^{(3)}$
}

(1)Embrapa Trigo, Caixa Postal 451, CEP 99001-970 Passo Fundo, RS. E-mail: hpsantos@cnpt.embrapa.br, renatof@cnpt.embrapa.br (2)Embrapa Agrossilvipastoril, Caixa Postal 343, CEP 78550-970 Sinop MT. E-mail: silvio.spera@embrapa.br (3)Linha Cinco Irmãos, Interior, s/no, CEP 99495-000 Lagoa dos Três Cantos, RS. E-mail: georgiamaldaner@yahoo.com.br

\begin{abstract}
Resumo - O objetivo deste trabalho foi avaliar a conversão e o balanço de energia em sistemas de produção com integração lavoura-pecuária, sob plantio direto. O experimento foi conduzido de 2001 a 2008. De 2001 a 2002, foram avaliados os sistemas: 1, trigo/soja e pastagem de aveia-preta+ervilhaca/milho; 2 , trigo/soja e pastagem de aveia-preta+ervilhaca+azevém/milho; 3 , trigo/soja e pastagem de aveia-preta+ervilhaca/pastagem de milheto; 4, trigo/soja e pastagem de aveia-preta+ervilhaca+azevém/pastagem de milheto; 5 , trigo/soja, aveia-branca/ soja e pastagem de aveia-preta+ervilhaca/pastagem de milheto; 6 , trigo/soja, aveia-branca/soja e pastagem de aveia-preta+ervilhaca+azevém/pastagem de milheto. De 2003 a 2008, foram avaliados os sistemas: 1, trigo/ soja e ervilhaca/milho; 2, trigo/soja e pastagem de aveia-preta/milho; 3 , trigo/soja e aveia-preta/soja; 4, trigo/ soja e ervilha/milho; 5, trigo/soja, ervilhaca/soja e triticale de duplo propósito/soja; e 6, trigo/soja, aveiabranca de duplo propósito/soja e trigo de duplo propósito/soja. O milho apresentou o maior retorno energético, em comparação às demais culturas produtoras de grãos e às pastagens de inverno e de verão. Das culturas de cobertura de solo e de adubação verde de inverno, a ervilha foi a mais eficiente na conversão de energia. Os sistemas 1, 2 e 4, entre 2003 e 2008, foram os mais eficientes no balanço energético.
\end{abstract}

Termos para indexação: adubação verde, pastagens de inverno, pastagens de verão, plantas de cobertura, retorno energético, rotação de culturas.

\section{Energy conversion and balance of integrated crop-livestock production systems under no-tillage}

\begin{abstract}
The objective of this work was to assess energy conversion and balance of integrated crop-livestock production systems, under no-tillage. The experiment was carried out from 2001 to 2008. From 2001 to 2002, the following systems were evaluated: 1 , wheat/soybean, and black oat pasture+common vetch/corn; 2 , wheat/ soybean, and black oat pasture+common vetch+ryegrass/corn; 3 , wheat/soybean and black oat pasture+common vetch/millet pasture; 4, wheat/soybean and black oat pasture+common vetch+rygrass/millet pasture; 5 , wheat/ soybean, white oat/soybean, and black oat pasture+common vetch/millet pasture; 6 , wheat/soybean, white oat/soybean, and black oat pasture+common vetch+rygrass/millet pasture. From 2003 to 2008, the following systems were evaluated: 1 , wheat/soybean, and common vetch/corn; 2, wheat/soybean, and black oat pasture/ corn; 3 , wheat/soybean, and black oat pasture/soybean; 4, wheat/soybean, and field pea/corn; 5 , wheat/soybean, common vetch/soybean, and double purpose triticale/soybean; and 6, wheat/soybean, double purpose white oat/soybean, and double purpose wheat/soybean. Corn showed highest returned energy in comparison to the other grain crops, and to winter and summer annual pastures. Of the winter cover crops and green manure species evaluated, field pea was the most efficient in energy conversion. Systems 1, 2, and 4, from 2003 to 2008, had the most efficient energy balance.
\end{abstract}

Index terms: green manure, winter pastures, summer pastures, cover crops, returned energy, crop rotation.

\section{Introdução}

No Brasil, pouca atenção tem-se dado a como os fluxos energéticos distribuem-se nos sistemas produtivos (Pinto, 2002; Campos et al., 2003; Campos \& Campos, 2004; Santos et al., 2004; Santos \& Fontaneli, 2007). Na agropecuária, o enfoque tem sido voltado a novas fontes de energia (biomassa), para a racionalização do uso de energia fóssil. Uma das formas de avaliação da disponibilidade e do consumo de energia é por meio da determinação da conversão e do balanço de energia.

Os primeiros trabalhos a contabilizar os processos para obtenção dos índices de energia disponível e de 
energia consumida com culturas produtoras de grãos (aveia-branca, cevada, milho, soja e trigo) foram relatados por Pimentel \& Burgess (1980). Autores como Briggle (1980), Bukantis \& Goodman (1980), Pimentel \& Burgess (1980), Scott \& Krummel (1980) e Weaver (1980) também estimaram índices de conversão energética de várias culturas, como aveia-branca $(4,44$ MJ ha $\left.{ }^{-1}\right)$, cevada (4,31 $\left.\mathrm{MJ} \mathrm{ha}^{-1}\right)$, milho (10,34 $\left.\mathrm{MJ} \mathrm{ha}^{-1}\right)$, soja (de 7,70 a 18,63 $\mathrm{MJ} \mathrm{ha}^{-1}$ ) e trigo (4,10 $\left.\mathrm{MJ} \mathrm{ha}^{-1}\right)$.

No Sul do Brasil, em culturas produtoras de grãos e de cobertura de solo, sob sistema plantio direto, Santos \& Reis (2003) obtiveram resultados com os seguintes índices de conversão: aveia-branca $(5,61$ a 5,78 $\left.\mathrm{MJ} \mathrm{ha}^{-1}\right)$, cevada $\left(5,36\right.$ a 6,07 $\left.\mathrm{MJ} \mathrm{ha}^{-1}\right)$, ervilhaca (0,63 $\left.\mathrm{MJ} \mathrm{ha}^{-1}\right)$, linho (2,89 a 3,01 $\mathrm{MJ}^{-1} \mathrm{ha}^{-1}$, milho $\left(14,11\right.$ a 15,65 $\left.\mathrm{MJ}^{-1}\right)$, soja $\left(7,12\right.$ a 7,95 $\left.\mathrm{MJ} \mathrm{ha}^{-1}\right)$, trigo (5,02 a 5,19 $\left.\mathrm{MJ} \mathrm{ha}^{-1}\right)$ e tremoço $\left(0,29 \mathrm{MJ} \mathrm{ha}^{-1}\right)$. Os autores também encontraram índices de conversão para sistemas de rotação de culturas: monocultura de cevada $\left(5,36 \mathrm{MJ} \mathrm{ha}^{-1}\right)$ e de trigo $\left(5,02 \mathrm{MJ} \mathrm{ha}^{-1}\right)$, rotação em um inverno (cevada, 6,03, e trigo, 5,06 $\mathrm{MJ} \mathrm{ha}^{-1}$ ), dois invernos de rotação (cevada, 5,69, e trigo, 5,19 MJ ha ${ }^{-1}$ ) e três invernos de rotação (cevada, 5,98, e trigo, 5,10 $\mathrm{MJ} \mathrm{ha}^{-1}$ ).

Trabalhos com espécies produtoras de grãos e com pastagens, tanto no inverno quanto no verão, em sistemas de produção com integração lavoura-pecuária (ILP), foram desenvolvidos por Santos et al. (2005b), em Coxilha, RS. Os autores observaram que os sistemas com trigo/soja e pastagem de aveia-preta+ervilhaca/ milho (20,63 e $72.329 \mathrm{MJ} \mathrm{ha}^{-1}$, respectivamente) e com trigo/soja e pastagem de aveia+ervilhaca+azevém/ milho (19,84 e $72.493 \mathrm{MJ} \mathrm{ha}^{-1}$, respectivamente) foram os mais eficientes na conversão e no balanço de energia.

O objetivo deste trabalho foi avaliar a conversão e o balanço de energia em sistemas de produção com integração lavoura-pecuária, sob sistema plantio direto.

\section{Material e Métodos}

O experimento, com sistemas de ILP, foi conduzido em área da Embrapa Trigo, no Município de Coxilha, RS, de 2001 a 2008, em solo classificado como Latossolo Vermelho distrófico típico (Streck et al., 2008). Foram obtidos dados de produtividade de grãos, produtividade de matéria seca, além de quantidade de $\mathrm{N}$ na matéria seca e de palha remanescente após o inverno.

Os tratamentos foram constituídos por seis sistemas de ILP. Em 2001 e 2003, foram avaliados os sistemas: 1, trigo (Triticum aestivum)/soja (Glycine max) e pastagem de aveia-preta (Avenastrigosa)+ervilhaca(Viciasativa)/ milho (Zea mays); 2, trigo/soja e pastagem de aveiapreta+ervilhaca+azevém (Lolium multiflorum)/milho; 3, trigo/soja e pastagem de aveia-preta+ervilhaca/ pastagem de milheto (Pennisetum glaucum); 4, trigo/ soja e pastagem de aveia-preta+ervilhaca+azevém/ pastagem de milheto; 5, trigo/soja, aveia-branca (Avena sativa)/soja e pastagem de aveia-preta+ervilhaca/ pastagem de milheto; e 6, trigo/soja, aveia-branca/ soja e pastagem de aveia-preta+ervilhaca+azevém/ pastagem de milheto. De 2003 a 2008, foram avaliados os sistemas: 1, trigo/soja e ervilhaca/milho; 2 , trigo/ soja e pastagem de aveia-preta/milho; 3 , trigo/soja e pastagem de aveia-preta/soja; 4, trigo/soja e ervilha (Pisum sativum)/milho; 5, trigo/soja, ervilhaca/soja e triticale (Triticum secale) de duplo propósito/soja; e 6, trigo/soja, aveia-branca de duplo propósito/soja e trigo de duplo propósito/soja (Tabela 1). Utilizou-se o delineamento experimental em blocos ao acaso, com quatro repetições. A área das parcelas foi de $200 \mathrm{~m}^{2}$ (10x20 m).

As culturas de inverno e verão foram manejadas com plantio direto. Os pastejos de aveia-branca, aveia-preta, trigo de duplo propósito e triticale foram realizados por bovinos mestiços (corte e leite), com carga animal estimada de 10 a 12 bovinos por hectare, quando as gramíneas atingiam estatura de aproximadamente $30 \mathrm{~cm}$. Na saída dos bovinos, a altura de resteva era de 7 a $10 \mathrm{~cm}$. Os pastejos foram utilizados somente em período sem excesso de umidade do solo, ou seja, uma ou duas vezes por ano.

A adubação de manutenção foi realizada de acordo com a indicação para cada cultura (Manual de adubação e de calagem para os estados do Rio Grande do Sul e de Santa Catarina, 2004) e baseada nos resultados de análise de solo. As amostras de solo foram coletadas anualmente, após a colheita das culturas de verão.

À época de semeadura, o controle de plantas daninhas e os tratamentos fitossanitários seguiram às indicações técnicas para cada cultura. A colheita das culturas produtoras de grãos foi efetuada com colhedora automotriz especial para parcelas experimentais, exceto a da cultura de milho, que foi realizada manualmente. 
As produtividades de grãos de aveia-branca, milho, soja, trigo e triticale foram corrigidas para umidade de $13 \%$.

A partir de matrizes de produção, procederam-se às transformações para contabilizar a energia disponível e consumida nesses processos. Para os cálculos dos diversos índices que envolvem os sistemas de produção sob ILP, como produtividades de grãos, produtividade de matéria seca, quantidade de palha remanescente, quantidade de $\mathrm{N}$ na matéria seca e operações de campo, foram empregados dados e orientações de Campos (2001), Santos et al. (2001), Bueno (2002), Pimentel et al. (2002), Pinto (2002), Pimentel (2004) e Santos $\&$ Fontaneli (2007). No caso da ervilha e da ervilhaca, foi considerada como produtividade a contribuição auferida com base no percentual de nitrogênio e palha da matéria seca. Os dados foram transformados para MJ (kcal x 1.000 x 4,186).

Como energia disponível ou receita energética $\left(\mathrm{MJ} \mathrm{ha}^{-1}\right)$, considerou-se a transformação em energia da produtividade de grãos, da produtividade de matéria seca, da quantidade de $\mathrm{N}$ na matéria seca e da quantidade de palha remanescente das espécies (Santos, et al., 2007). Como energia consumida (MJ ha-1), estimou-se a soma dos coeficientes energéticos correspondentes aos corretivos, fertilizantes, sementes, fungicidas e inseticidas usados em cada sistema de produção, bem como a energia consumida pelas operações (semeadura, adubação, aplicação de pesticidas e colheita). A conversão energética foi obtida pela divisão da energia disponível pela consumida, em cada sistema de produção com ILP. Já o balanço energético, foi resultante da diferença entre a energia disponível e a consumida em cada sistema de ILP.

Os períodos de 2001 a 2002 e de 2003 a 2008 foram avaliados separadamente, pois houve mudanças nas sequências de culturas dos sistemas de rotação.

Foi realizada análise de variância da conversão e do balanço energético, em cada ano (inverno + verão) e na média conjunta dos anos, nos períodos de 2001 a 2002 e de 2003 a 2008, sendo considerada a energia disponível e consumida pelas culturas que compuseram os sistemas de produção com ILP. Nas análises conjuntas, os tratamentos foram considerados como efeito fixo e o efeito do ano como aleatório. Utilizou-se o SAS versão 8.2 (SAS Institute, 2003), e as médias foram avaliadas pelo teste de Duncan, a 5\% de probabilidade.

\section{Resultados e Discussão}

As análises de variância da conversão e do balanço energéticos do conjunto dos anos, principalmente do segundo período, apresentaram efeito significativo para anos e sistemas de ILP (Tabelas 2 e 3). Santos et al. (2000) obtiveram resultados semelhantes para conversão e balanço energético. Quanto à conversão energética das culturas de inverno e verão, nos seis sistemas de ILP, houve diferença significativa entre as médias de cada ano e entre as médias dos dois períodos. No período de 2001 e 2002, entre as culturas de grãos avaliadas, o milho, a soja e o trigo foram mais eficientes que a aveia-branca e as pastagens de inverno, e tiveram

Tabela 1. Caracterização ${ }^{(1)}$ dos sistemas de produção com integração lavoura-pecuária (ILP) utilizados, sob plantio direto.

\begin{tabular}{|c|c|c|c|c|c|c|c|c|}
\hline Sistema & $2001 / 2002$ & $2002 / 2003$ & $2003 / 2004$ & $2004 / 2005$ & $2005 / 2006$ & $2006 / 2007$ & $2007 / 2008$ & $2008 / 2009$ \\
\hline \multirow{2}{*}{1} & $\mathrm{~T} / \mathrm{S}$ & $\mathrm{Ap}+\mathrm{E} / \mathrm{M}$ & $\mathrm{T} / \mathrm{S}$ & $\mathrm{E} / \mathrm{M}$ & $\mathrm{T} / \mathrm{S}$ & $\mathrm{E} / \mathrm{M}$ & $\mathrm{T} / \mathrm{S}$ & $\mathrm{E} / \mathrm{M}$ \\
\hline & $\mathrm{Ap}+\mathrm{E} / \mathrm{M}$ & $\mathrm{T} / \mathrm{S}$ & $\mathrm{E} / \mathrm{M}$ & $\mathrm{T} / \mathrm{S}$ & $\mathrm{E} / \mathrm{M}$ & $\mathrm{T} / \mathrm{S}$ & $\mathrm{E} / \mathrm{M}$ & $\mathrm{T} / \mathrm{S}$ \\
\hline \multirow{2}{*}{2} & $\mathrm{~T} / \mathrm{S}$ & $\mathrm{Ap}+\mathrm{E}+\mathrm{Az} / \mathrm{M}$ & $\mathrm{T} / \mathrm{S}$ & $\mathrm{Ap} / \mathrm{M}$ & $\mathrm{T} / \mathrm{S}$ & $\mathrm{Ap} / \mathrm{M}$ & $\mathrm{T} / \mathrm{S}$ & $\mathrm{Ap} / \mathrm{M}$ \\
\hline & $\mathrm{Ap}+\mathrm{E}+\mathrm{Az} / \mathrm{M}$ & $\mathrm{T} / \mathrm{S}$ & $\mathrm{Ap} / \mathrm{M}$ & $\mathrm{T} / \mathrm{S}$ & $\mathrm{Ap} / \mathrm{M}$ & $\mathrm{T} / \mathrm{S}$ & $\mathrm{Ap} / \mathrm{M}$ & $\mathrm{T} / \mathrm{S}$ \\
\hline \multirow{2}{*}{3} & $\mathrm{~T} / \mathrm{S}$ & $\mathrm{Ap}+\mathrm{E} / \mathrm{Mi}$ & $\mathrm{T} / \mathrm{S}$ & $\mathrm{Ap} / \mathrm{S}$ & $\mathrm{T} / \mathrm{S}$ & $\mathrm{A} / \mathrm{S}$ & $\mathrm{T} / \mathrm{S}$ & $\mathrm{Ap} / \mathrm{S}$ \\
\hline & $\mathrm{Ap}+\mathrm{E} / \mathrm{Mi}$ & $\mathrm{T} / \mathrm{S}$ & $\mathrm{Ap} / \mathrm{S}$ & $\mathrm{T} / \mathrm{S}$ & $\mathrm{Ap} / \mathrm{S}$ & $\mathrm{T} / \mathrm{S}$ & $\mathrm{Ap} / \mathrm{S}$ & $\mathrm{T} / \mathrm{S}$ \\
\hline \multirow{2}{*}{4} & $\mathrm{~T} / \mathrm{S}$ & $\mathrm{Ap}+\mathrm{E}+\mathrm{Az} / \mathrm{Mi}$ & $\mathrm{T} / \mathrm{S}$ & $\mathrm{Er} / \mathrm{M}$ & $\mathrm{T} / \mathrm{S}$ & $\mathrm{Er} / \mathrm{M}$ & $\mathrm{T} / \mathrm{S}$ & $\mathrm{Er} / \mathrm{M}$ \\
\hline & $\mathrm{Ap}+\mathrm{E}+\mathrm{Az} / \mathrm{Mi}$ & $\mathrm{T} / \mathrm{S}$ & $\mathrm{Er} / \mathrm{M}$ & $\mathrm{T} / \mathrm{S}$ & $\mathrm{Er} / \mathrm{M}$ & $\mathrm{T} / \mathrm{S}$ & $\mathrm{Er} / \mathrm{M}$ & $\mathrm{T} / \mathrm{S}$ \\
\hline \multirow{3}{*}{5} & $\mathrm{~T} / \mathrm{S}$ & $\mathrm{Ab} / \mathrm{S}$ & $\mathrm{E} / \mathrm{S}$ & $\mathrm{T} / \mathrm{S}$ & $\mathrm{Tl} / \mathrm{S}$ & $\mathrm{E} / \mathrm{S}$ & $\mathrm{T} / \mathrm{S}$ & $\mathrm{Tl} / \mathrm{S}$ \\
\hline & $\mathrm{Ab} / \mathrm{S}$ & $\mathrm{Ap}+\mathrm{E} / \mathrm{Mi}$ & $\mathrm{T} / \mathrm{S}$ & $\mathrm{Tl} / \mathrm{S}$ & $\mathrm{E} / \mathrm{S}$ & $\mathrm{T} / \mathrm{S}$ & $\mathrm{Tl} / \mathrm{S}$ & $\mathrm{E} / \mathrm{S}$ \\
\hline & $\mathrm{Ap}+\mathrm{E} / \mathrm{Mi}$ & $\mathrm{T} / \mathrm{S}$ & $\mathrm{Tl} / \mathrm{S}$ & $\mathrm{E} / \mathrm{S}$ & $\mathrm{T} / \mathrm{S}$ & $\mathrm{Tl} / \mathrm{S}$ & $\mathrm{E} / \mathrm{S}$ & $\mathrm{T} / \mathrm{S}$ \\
\hline \multirow{3}{*}{6} & $\mathrm{~T} / \mathrm{S}$ & $\mathrm{Ab} / \mathrm{S}$ & $\mathrm{Td} / \mathrm{S}$ & $\mathrm{T} / \mathrm{S}$ & $\mathrm{Abd} / \mathrm{S}$ & $\mathrm{Td} / \mathrm{S}$ & $\mathrm{T} / \mathrm{S}$ & $\mathrm{Abd} / \mathrm{S}$ \\
\hline & $\mathrm{Ab} / \mathrm{S}$ & $\mathrm{Ap}+\mathrm{E} / \mathrm{Mi}$ & $\mathrm{T} / \mathrm{S}$ & $\mathrm{Abd} / \mathrm{S}$ & $\mathrm{Td} / \mathrm{S}$ & $\mathrm{T} / \mathrm{S}$ & $\mathrm{Abd} / \mathrm{S}$ & $\mathrm{Td} / \mathrm{S}$ \\
\hline & $\mathrm{Ap}+\mathrm{E} / \mathrm{Mi}$ & $\mathrm{T} / \mathrm{S}$ & $\mathrm{Abd} / \mathrm{S}$ & $\mathrm{Td} / \mathrm{S}$ & $\mathrm{T} / \mathrm{S}$ & $\mathrm{Abd} / \mathrm{S}$ & $\mathrm{Td} / \mathrm{S}$ & $\mathrm{T} / \mathrm{S}$ \\
\hline
\end{tabular}

${ }^{(1)} \mathrm{Ab}$, aveia-branca; Abd, aveia-branca de duplo propósito; Ap, aveia-preta; Az, azevém; Er, ervilha; E, ervilhaca; M, milho; Mi, milheto; S, soja; Tl, triticale de duplo propósito; T, trigo; Td, trigo de duplo propósito. 
desempenho semelhante ao do milheto (Tabela 2). $\mathrm{O}$ milheto foi a espécie mais eficiente das pastagens, em comparação à aveia-preta +ervilhaca e à aveiapreta+ervilhaca+azevém.

No período de 2003 a 2008, entre as culturas de inverno, a ervilha foi a mais eficiente na conversão de energia (Tabela 2). A ervilha foi semeada sem adubação de manutenção e praticamente não sofreu nenhum ataque de doença ou praga, durante esse período. A ervilha e a ervilhaca foram semeadas como planta de cobertura do solo, para produzir palha e adubação verde. Observou-se que a ervilhaca não produziu, ao longo dos anos, tanta biomassa quanto a ervilha e apresentou menor percentual de nitrogênio. No caso das leguminosas de cobertura de solo e de adubação verde, o dispêndio de energia fóssil na produção foi menor, principalmente em razão da ausência da aplicação de fertilizantes. A aveia-preta, que é semeada solteira, para pastejo, foi a espécie de menor retorno energético. Das espécies produtoras de grãos de inverno e verão, o milho, o trigo, a soja, a aveia-branca de duplo propósito e o trigo de duplo propósito apresentaram conversão energética intermediária. $\mathrm{O}$ triticale de duplo propósito não diferiu das demais espécies que foram pastejadas com dupla finalidade, de 2003 a 2008, para ofertar biomassa aos animais e produzir grãos, como foi o caso da aveia-branca, de uma cultivar de trigo e do triticale.

De 2003 a 2008, os índices de conversão energética foram superiores à unidade, o que significa que houve conversão positiva de energia. Entretanto, em trabalho realizado anteriormente por Santos et al. (2005a), no período de 1995 a 2000, as pastagens de aveia-preta +ervilhaca $(0,77)$, de aveia-preta+ervilhaca+azevém $(0,65)$ e de milheto $(0,90)$ apresentaram conversão

Tabela 2. Conversão energética da produtividade de matéria seca das culturas e dos sistemas de produção integração lavoura-pecuária, sob plantio direto, na média dos anos de 2001 a $2008^{(1)}$.

\begin{tabular}{|c|c|c|c|c|c|c|c|c|c|c|}
\hline \multirow[t]{2}{*}{ Variável } & \multicolumn{2}{|c|}{ Ano } & \multirow[t]{2}{*}{ Média } & \multicolumn{6}{|c|}{ Ano } & \multirow[t]{2}{*}{ Média } \\
\hline & 2001 & 2002 & & 2003 & 2004 & 2005 & 2006 & 2007 & 2008 & \\
\hline & \multicolumn{10}{|c|}{ Conversão energética das culturas ${ }^{(2)}$} \\
\hline $\mathrm{Ab}$ & $43,45 \mathrm{c}$ & $61,66 b$ & $52,58 b$ & - & - & - & - & - & - & - \\
\hline Abd (duplo propósito) & - & - & - & $35,75 c$ & $28,00 \mathrm{~d}$ & $39,68 \mathrm{~d}$ & $30,10 \mathrm{c}$ & $35,04 \mathrm{c}$ & $41,23 \mathrm{~cd}$ & $34,99 d$ \\
\hline Ap (pastagens) & - & - & - & $30,52 \mathrm{~cd}$ & $19,93 \mathrm{e}$ & $25,37 \mathrm{e}$ & $19,76 \mathrm{~cd}$ & $21,20 \mathrm{~d}$ & $23,11 d$ & $28,76 \mathrm{e}$ \\
\hline$A p+E$ (pastagens) & $39,68 \mathrm{c}$ & $26,87 \mathrm{c}$ & $33,28 \mathrm{c}$ & - & - & - & - & - & - & - \\
\hline$A p+E+A z$ (pastagens) & $40,19 c$ & $28,13 \mathrm{c}$ & $34,16 \mathrm{c}$ & - & - & - & - & - & - & - \\
\hline Ervilha & - & - & - & - & $116,29 \mathrm{a}$ & $84,14 a$ & $14,44 d$ & $83,89 a$ & $101,76 \mathrm{a}$ & $80,12 \mathrm{a}$ \\
\hline Ervilhaca & - & - & - & $70,49 a$ & $53,12 b$ & $48,89 \mathrm{bc}$ & $17,92 d$ & $40,44 \mathrm{bc}$ & $45,67 \mathrm{c}$ & $46,09 \mathrm{bc}$ \\
\hline Milho & $67,94 a$ & $63,50 \mathrm{~b}$ & $65,72 \mathrm{a}$ & $58,94 \mathrm{~b}$ & $10,17 f$ & $84,72 \mathrm{a}$ & $73,34 a$ & $34,53 \mathrm{c}$ & $80,41 b$ & $57,01 b$ \\
\hline Milheto (pastagem) & $71,87 \mathrm{a}$ & $57,93 b$ & $64,88 \mathrm{a}$ & - & - & - & - & - & - & - \\
\hline Soja & $51,66 b$ & $78,40 \mathrm{a}$ & $68,24 a$ & $23,19 d$ & $0,00 \mathrm{~g}$ & $41,36 \mathrm{~cd}$ & $73,67 \mathrm{a}$ & $18,63 d$ & $91,97 \mathrm{ab}$ & $41,44 \mathrm{~cd}$ \\
\hline Tl (duplo propósito) & - & - & - & $28,72 \mathrm{~cd}$ & $30,80 d$ & $34,66 \mathrm{~d}$ & $23,94 \mathrm{~cd}$ & $41,61 b c$ & $37,51 \mathrm{~cd}$ & $32,86 \mathrm{de}$ \\
\hline Trigo & $59,99 b$ & $66,64 b$ & $63,33 a$ & $56,89 b$ & $47,88 \mathrm{c}$ & $55,63 b$ & $46,92 b$ & $37,30 \mathrm{c}$ & $43,33 \mathrm{~cd}$ & $48,05 \mathrm{bc}$ \\
\hline Td (duplo propósito) & - & - & - & $32,73 \mathrm{~cd}$ & $32,65 \mathrm{~d}$ & $49,60 \mathrm{bc}$ & $30,12 \mathrm{c}$ & $46,63 b$ & $55,05 \mathrm{c}$ & $41,15 \mathrm{~cd}$ \\
\hline Média & 53,54 & 58,31 & 54,12 & 42,15 & 37,67 & 51,57 & 36,67 & 40,35 & 57,76 & 45,59 \\
\hline CV (\%) & 17 & 24 & - & 27 & 18 & 15 & 19 & 23 & 26 & - \\
\hline \multirow[t]{2}{*}{ Significância } & $* *$ & $* *$ & $* *$ & $* *$ & $* *$ & $* *$ & $* *$ & $* *$ & $* *$ & $* *$ \\
\hline & \multicolumn{10}{|c|}{ Conversão energética dos sistemas ${ }^{(3)}$} \\
\hline 1 & 57,14 & 59,32 & 58,23 & $48,77 \mathrm{a}$ & 23,15 & $62,87 \mathrm{a}$ & 54,63 & $34,37 \mathrm{ab}$ & 73,42 & $49,52 \mathrm{a}$ \\
\hline 2 & 58,77 & 58,35 & 58,56 & $49,77 \mathrm{a}$ & 20,39 & $56,93 \mathrm{a}$ & 51,86 & $30,93 b$ & 57,39 & $44,54 b$ \\
\hline 3 & 58,19 & 57,47 & 57,81 & $32,94 b$ & 19,59 & $43,62 b$ & 53,33 & $24,82 \mathrm{c}$ & 63,42 & $39,64 \mathrm{c}$ \\
\hline 4 & 57,18 & 56,18 & 56,68 & $50,48 \mathrm{a}$ & 28,67 & $63,00 \mathrm{a}$ & 57,43 & $37,67 \mathrm{a}$ & 75,15 & $52,12 \mathrm{a}$ \\
\hline 5 & 53,25 & 65,85 & 59,16 & $41,48 \mathrm{ab}$ & 20,64 & $45,00 \mathrm{~b}$ & 55,72 & $29,13 b c$ & 64,92 & $42,82 \mathrm{bc}$ \\
\hline 6 & 56,51 & 57,85 & 57,18 & $31,48 \mathrm{~b}$ & 21,31 & $44,41 \mathrm{~b}$ & 52,03 & $29,16 b c$ & 66,01 & $40,71 \mathrm{bc}$ \\
\hline Média & 56,80 & 59,15 & 57,97 & 42,49 & 22,27 & 52,62 & 54,17 & 31,06 & 66,77 & 44,92 \\
\hline CV (\%) & 13 & 30 & - & 27 & 30 & 23 & 17 & 18 & 23 & - \\
\hline Significância & ns & ns & ns & $* *$ & ns & $* *$ & ns & $* *$ & $\mathrm{~ns}$ & $* *$ \\
\hline
\end{tabular}

${ }^{(1)}$ Médias seguidas de letras iguais, nas colunas, não diferem pelo teste de Duncan, a 5\% de probabilidade. ${ }^{(2)} \mathrm{Ab}$, aveia-branca; ${ }^{3)} \mathrm{Abd}$, aveia-branca de duplo propósito; Ap, aveia-preta; Az, azevém; E, ervilhaca; T1, triticale de duplo propósito; Td, trigo de duplo propósito. ${ }^{(4)}$ Sistemas de acordo com a Tabela 1.

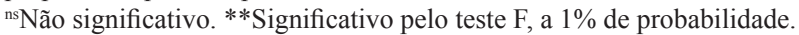


negativa. Hetz \& Melo (1997), ao considerar a palha remanescente das espécies estudadas, observaram que a produtividade de grãos das culturas de milho e trigo e, consequentemente, da eficiência energética do sistema plantio direto aumentou com o passar do tempo. Portanto, o rendimento energético é dependente do nível tecnológico empregado. Carmo et al. (1988), ao avaliar o cultivo de diferentes produtos, encontraram balanços energéticos muito diferentes entre propriedades, sendo os grãos o produto de maior retorno por unidade calórica investida, e as hortaliças e os produtos animais, exceto o mel, os de menor.

$\mathrm{Na}$ análise dos sistemas de produção sob ILP, em vez das culturas isoladamente, não houve diferença entre os anos e entre as médias dos anos para os índices de conversão energética, no período de 2001 a 2002 (Tabela 2). Contudo, no período de 2003 a 2008, em três dos seis anos estudados, houve diferença entre os sistemas de ILP na conversão anual (inverno + verão) e na média de conversão dos anos. Na média dos anos, os sistemas 1 e 4 foram os mais eficientes energeticamente. O sistema 2 situou-se em uma posição intermediária quanto aos índices de conversão energética. Os sistemas 3,5 e 6 não diferiram entre si. É provável que a diferença a favor dos sistemas 1 e 4 esteja relacionada à presença da cultura de milho. O milho foi antecedido por culturas de adubação de inverno, que não receberam adubação de manutenção, o que consumiu menos energia e proporcionou mais energia disponível aos sistemas e ao milho, que foi cultivado sem adubação nitrogenada de cobertura. Isso tornou os sistemas 1 e 4 mais eficientes energeticamente e repercutiu diretamente na conversão energética dos sistemas. Resultados semelhantes foram obtidos por Santos et al. (2005c).

Todos os sistemas de produção sob ILP apresentaram conversões energéticas superiores à unidade $(1,0)$ e

Tabela 3. Balanço energético da produtividade de matéria seca e das culturas e dos sistemas de integração lavoura-pecuária, sob plantio direto, na média dos anos, de 2001 a $2008^{(1)}$.

\begin{tabular}{|c|c|c|c|c|c|c|c|c|c|c|}
\hline \multirow[t]{2}{*}{ 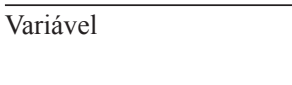 } & \multicolumn{2}{|c|}{ Ano } & \multirow[t]{2}{*}{ Média } & \multicolumn{6}{|c|}{ Ano } & \multirow{2}{*}{ Média } \\
\hline & 2001 & 2002 & & 2003 & 2004 & 2005 & 2006 & 2007 & 2008 & \\
\hline & \multicolumn{10}{|c|}{ Balanço energético das culturas $\left(\mathrm{MJ} \mathrm{ha}^{-1}\right)^{(2)}$} \\
\hline $\mathrm{Ab}$ & $81.514 \mathrm{~d}$ & $144.982 \mathrm{a}$ & $113.248 b$ & - & - & - & - & - & - & - \\
\hline Abd (duplo propósito) & - & - & - & $77.274 \mathrm{bc}$ & $63.870 \mathrm{~b}$ & $72.152 d$ & $50.751 \mathrm{c}$ & $66.645 \mathrm{c}$ & $72.539 \mathrm{cde}$ & 67.206 \\
\hline Ap (pastagens) & - & - & - & $32.848 \mathrm{~d}$ & $24.057 \mathrm{c}$ & $35.284 \mathrm{f}$ & $34.338 \mathrm{c}$ & $39.482 \mathrm{e}$ & $41.676 \mathrm{ef}$ & 28.038 \\
\hline Ap $+E$ (pastagens) & $63.703 \mathrm{e}$ & $42.341 \mathrm{c}$ & $53.020 \mathrm{c}$ & - & - & - & - & - & - & - \\
\hline $\mathrm{Ap}+\mathrm{E}+\mathrm{Az}$ (pastagens) & $71.208 \mathrm{de}$ & $49.052 \mathrm{c}$ & $60.132 \mathrm{c}$ & - & - & - & - & - & - & - \\
\hline Ervilha & - & - & - & - & $62.673 b$ & $51.396 \mathrm{e}$ & $6.852 \mathrm{~d}$ & $51.249 \mathrm{~d}$ & $65.331 \mathrm{de}$ & 47.503 \\
\hline Ervilhaca & - & - & - & $42.643 d$ & $26.933 c$ & $28.741 \mathrm{f}$ & $9.180 \mathrm{~d}$ & $23.308 \mathrm{f}$ & $27.778 f$ & 26.430 \\
\hline Milho & $151.659 \mathrm{a}$ & $148.168 \mathrm{a}$ & $149.913 \mathrm{a}$ & $125.735 \mathrm{a}$ & $15.078 \mathrm{~d}$ & $193.000 \mathrm{a}$ & $171.777 \mathrm{a}$ & $77.156 b c$ & $196.709 a$ & 129.992 \\
\hline Milheto (pastagem) & $109.615 b$ & $94.348 b$ & $101.979 b$ & - & - & - & - & - & - & - \\
\hline Soja & $94.809 \mathrm{c}$ & $129.967 \mathrm{a}$ & $112.390 \mathrm{~b}$ & $25.417 \mathrm{~d}$ & $-6.036 \mathrm{e}$ & $53.870 \mathrm{e}$ & $100.271 \mathrm{~b}$ & $21.851 \mathrm{f}$ & $148.180 \mathrm{~b}$ & 57.256 \\
\hline $\mathrm{Tl}$ (duplo propósito) & - & - & - & $74.247 \mathrm{c}$ & $70.266 \mathrm{~b}$ & $64.008 \mathrm{de}$ & $40.027 \mathrm{c}$ & $86.910 \mathrm{ab}$ & $73.724 \mathrm{cde}$ & 64.012 \\
\hline Trigo & $81.234 \mathrm{~d}$ & $126.241 \mathrm{a}$ & $103.737 b$ & $84.180 \mathrm{~b}$ & $83.783 \mathrm{a}$ & $107.894 \mathrm{~b}$ & $89.375 b$ & $70.760 \mathrm{c}$ & $81.903 \mathrm{~cd}$ & 86.315 \\
\hline Td (duplo propósito) & - & - & - & $67.533 \mathrm{bc}$ & $70.789 b$ & $88.467 \mathrm{c}$ & $48.742 \mathrm{c}$ & $93.356 \mathrm{a}$ & $104.872 \mathrm{c}$ & 78.961 \\
\hline Média & 97.576 & 105.014 & 99.200 & 66.235 & 45.711 & 77.198 & 61.258 & 58.968 & 90.300 & 65.536 \\
\hline$\overline{\mathrm{CV}(\%)}$ & 18 & 29 & - & 30 & 23 & 16 & 20 & 20 & 28 & - \\
\hline \multirow[t]{2}{*}{ Significância } & $* *$ & $* *$ & $* *$ & $* *$ & $* *$ & $* *$ & $* *$ & $* *$ & $* *$ & ns \\
\hline & \multicolumn{10}{|c|}{ Balanço energético dos sistemas $\left(\mathrm{MJ} \mathrm{ha}^{-1}\right)^{(3)}$} \\
\hline 1 & 191.293 & 220.724 & 206.001 & $130.988 \mathrm{ab}$ & 61.626 & $189.848 \mathrm{a}$ & 167.637 & $102.854 \mathrm{ab}$ & 240.302 & $148.854 \mathrm{a}$ \\
\hline 2 & 204.248 & 220.301 & 212.276 & $148.025 \mathrm{ab}$ & 57.775 & $202.406 \mathrm{a}$ & 193.929 & $108.112 \mathrm{a}$ & 222.863 & $155.543 \mathrm{a}$ \\
\hline 3 & 176.984 & 198.182 & 187.583 & $80.798 d$ & 50.471 & $133.245 b$ & 176.218 & $73.167 \mathrm{c}$ & 222.478 & $122.734 b$ \\
\hline 4 & 177.976 & 196.734 & 187.353 & $151.960 \mathrm{a}$ & 78.584 & $189.542 \mathrm{a}$ & 177.378 & $113.131 \mathrm{a}$ & 246.430 & $159.487 \mathrm{a}$ \\
\hline 5 & 168.265 & 242.817 & 205.541 & $116.572 \mathrm{bc}$ & 54.163 & $124.647 b$ & 155.288 & $82.573 b c$ & 191.710 & $120.808 b$ \\
\hline 6 & 183.200 & 211.586 & 197.395 & $93.080 \mathrm{~cd}$ & 64.176 & $139.653 b$ & 163.928 & $92.628 \mathrm{abc}$ & 226.366 & $130.000 \mathrm{~b}$ \\
\hline Média & 183.661 & 215.056 & 199.358 & 120.239 & 61.132 & 163.221 & 172.396 & 95.407 & 225.023 & 139.561 \\
\hline $\mathrm{CV}(\%)$ & 14 & 32 & - & 29 & 38 & 25 & 20 & 24 & 22 & - \\
\hline Significância & ns & ns & ns & $* *$ & ns & $* *$ & ns & $* *$ & ns & $* *$ \\
\hline
\end{tabular}


produziram 10,55 a 12,73 vezes mais energia do que a energia não renovável consumida. Segundo Quesada \& Costa Beber (1990), esse resultado caracteriza um balanço energético positivo e sustentado entre os sistemas estudados.

No que se refere ao balanço energético isolado da produtividade de matéria seca das culturas de inverno e verão, houve diferenças significativas entre as médias dos sistemas e as médias dos anos. No período de 2001 e 2002, o milho foi a cultura mais eficiente na conversão de energia (Tabela 3). Resultados semelhantes foram encontrados por Hetz \& Melo (1997), Santos \& Reis (2003) e Santos et al. (2007). A aveia-branca, o milheto, o trigo e a soja apresentaram índices de balanço energético intermediários.

As pastagens de aveia-preta+ervilhaca e de aveiapreta+ervilhaca+azevém apresentaram os menores retornos energéticos (Tabela 3). No período de 2003 a 2008, não houve diferença nos índices de balanço energético das espécies estudadas. O destaque, em valores absolutos, foi a cultura do milho, que apresentou a maior conversão de energia. $O$ trigo, a soja e as culturas de duplo propósito (aveia-branca, trigo e triticale) tiveram índices de retorno energético inferiores. As culturas de cobertura do solo (ervilha e ervilhaca) e a pastagem de aveia-preta foram as de menor retorno energético. Porém, todas as espécies estudadas, tanto no inverno como no verão, consumiram menos energia do que retiraram do sistema.

$\mathrm{Na}$ análise dos sistemas de produção sob ILP, em três dos oito anos estudados, na conversão anual (inverno+verão) e na média dos anos, houve diferença entre os sistemas de produção com ILP (Tabela 3). Na média dos anos, os sistemas 1, 2, e 4 foram os mais eficientes energeticamente. Em parte, a maior diferença do balanço energético, em comparação aos demais sistemas, deve-se à cultura do milho que foi a espécie de mais elevado retorno energético. Santos et al. (2005c) obtiveram resultados de balanço energético semelhantes em sistemas de ILP, com a cultura de milho. Em termos gerais, o resultado de balanço energético repetiu o de conversão energética nos sistemas 1 e 2 . Como os sistemas estudados apresentaram balanço energético positivo, eles podem ser considerados como sustentáveis do ponto de vista energético. Além disso, os sistemas de produção sob ILP foram mais eficientes energeticamente do que as culturas isoladas.

No experimento de Santos et al. (2001), durante nove anos, com sistemas de rotação de culturas sob preparo convencional do solo, no inverno, e semeadura direta, no verão, em sistemas de rotação com um, dois e três invernos sem trigo, os índices de balanço energético foram maiores que o de pousio de inverno. No entanto, os autores não verificaram diferenças entre os sistemas com rotação de culturas e a monocultura, em relação ao balanço energético.

De acordo com os resultados deste trabalho, pode-se afirmar que a tecnologia agrícola aplicada aos sistemas avaliados é eficiente em termos de conversão e de balanço energético. No caso dos sistemas de produção, destacaram-se os sistemas 1, 2 e 4 . Contudo, o consumo de energia pode aumentar com mudanças na tecnologia de produção (Bueno, 2002).

\section{Conclusões}

1. A cultura de milho apresenta o maior retorno energético, em comparação às demais culturas produtoras de grãos e às pastagens de inverno e de verão avaliadas.

2. Entre as culturas de cobertura de solo e de adubação verde de inverno, a ervilha é a mais eficiente na conversão de energia.

3. Os sistemas de integração lavoura-pecuária sob sistema plantio direto são mais eficientes energeticamente do que as culturas isoladas, e possuem conversão e balanço energético positivos.

\section{Referências}

BRIGGLE, L.W. Introduction to energy use in wheat production. In: PIMENTEL, D. (Ed.). Handbook of energy utilization in agriculture. Boca Raton: CRC, 1980. p.109-116.

BUENO, O. de C. Análise energética e eficiência cultural do milho em assentamento rural, Itaberá, SP. 2002. 141p. Tese (Doutorado) - Universidade Estadual Paulista, Botucatu.

BUKANTIS, P.; GOODMAN, N. Energy inputs in barley production. In: PIMENTEL, D. (Ed.). Handbook of energy utilization in agriculture. Boca Raton: CRC, 1980. p.59-65.

CAMPOS, A.T. Balanço energético relativo à produção de feno de "coast-cross" e alfafa em sistema intensivo de produção de leite. 2001. 243p. Tese (Doutorado) - Universidade Estadual Paulista, Botucatu.

CAMPOS, A.T.; CAMPOS, A.T. de. Balanços energéticos agropecuários: uma importante ferramenta como indicativo de sustentabilidade de agroecossistemas. Ciência Rural, v.34, p.1977-1985, 2004.

CAMPOS, A.T.; SAGLIETTI, J.R.C.; CAMPOS, A.T. de; BUENO, O. de C.; RESENDE, H.; GASPARINO, E.; KLOSOWSKI, E.S. Custo energético de construção de uma 
instalação para armazenagem de feno. Ciência Rural, v.33, p.667-672, 2003.

CARMO, M.S.; COMITRE, V.; DULLEY, R.D. Balanço energético de sistemas de produção na agricultura alternativa. Agricultura em São Paulo, v.35, p.87-97, 1988.

HETZ, E.J.; MELO, L.A. Evaluación energética de un sistema de producción de maíz y trigo com cero labranza: el caso de Chequén, Concepción, Chile. Agro-Ciencia, v.13, p.181-187, 1997.

MANUAL de adubação e de calagem para os estados do Rio Grande do Sul e de Santa Catarina. 10.ed. Porto Alegre: SBSC, 2004. 394p.

PIMENTEL, D. Livestock production and energy use. In: MATSUMURA, R. (Ed.). Encyclopedia of energy. San Diego: Elsevier, 2004. p.671-676.

PIMENTEL, D.; BURGESS, M. Energy inputs in corn production. In: PIMENTEL, D. (Ed.). Handbook of energy utilization in agriculture. Boca Raton: CRC, 1980. p.67-84.

PIMENTEL, D.; DOUGHTY, R.; CAROTHERS, C.; LAMBERSON, S.; BORA, N.; LEE, K. Energy inputs in crop production: comparison of developed and developing countries. In: LAL, R.; HANSEN, D.; UPHOFF, N.; SLACK, S.A. (Ed.). Food security and environmental quality in the developing world. Boca Raton: CRC, 2002. p.129-151.

PINTO, M.S.V. Análise econômica e energética de sistema agroflorestal para implantação na terra indígena Aratibá Município de Avaí - SP. 2002. 136p. Dissertação (Mestrado) Universidade Estadual Paulista, Botucatu.

QUESADA, G.M.; COSTA BEBER, J.A. Energia e mão-de-obra. Ciência Hoje, v.11, p.21-26, 1990.

SANTOS, H.P. dos; FONTANELI, R.S. Conversão e balanço energético de sistemas de produção de grãos de milho sob plantio direto. In: SANTOS, H.P. dos; FONTANELI. R.S.; SPERA, S.T. (Org.). Sistema de produção para milho, sob plantio direto. Passo Fundo: Embrapa Trigo, 2007. p.297-312.

SANTOS, H.P. dos; FONTANELI, R.S.; BAIER, A.C.; TOMM, G.O. Principais forrageiras para integração lavoura-pecuária, sob plantio direto, nas Regiões Planalto e Missões do Rio Grande do Sul. Passo Fundo: Embrapa Trigo, 2005a. 142p.
SANTOS, H.P. dos; FONTANELI, R.S.; IGNACZAK, J.C.; ZOLDAN, S.M. Conversão e balanço energético de sistemas de produção de grãos com pastagens sob sistema plantio direto. Pesquisa Agropecuária Brasileira, v.35, p.743-752, 2000.

SANTOS, H.P. dos; FONTANELI, R.S.; SPERA, S.T.; TOMM, G.O.; AMBROSI, I. Sistemas de produção de grãos com pastagens anuais de inverno e de verão, sob plantio direto. Passo Fundo: Embrapa Trigo, 2004. 39p. (Embrapa Trigo. Documentos, 45).

SANTOS, H.P. dos; FONTANELI, R.S.; TOMM, G.O.; MANTO, L. Conversão e balanço energético de culturas de inverno e de verão em sistemas de produção mistos sob plantio direto. Pesquisa Agropecuária Gaúcha, v.11, p.39-46, 2005 b.

SANTOS, H.P. dos; IGNACZAK, J.C.; FONTANELI, R.S. Conversão e balanço energético de modelos de produção para soja, sob plantio direto. In: SANTOS, H.P. dos; FONTANELI, R.S.; SPERA, S.T.; PIRES, J.L.; TOMM, G.O. (Org.). Eficiência de soja cultivada em modelos de produção sob sistema plantio direto. Passo Fundo: Embrapa Trigo, 2005c. p.201-220.

SANTOS, H.P. dos; LHAMBY, J.C.B.; IGNACZAK, J.C.; SCHNEIDER, G.A. Conversão e balanço energético de sistemas de sucessão e de rotação de culturas. Ciência Rural, v.31, p.191-198, 2001.

SANTOS, H.P. dos; REIS, E.M. Rotação de culturas. In: SANTOS, H.P. dos; REIS, E.M. Rotação de culturas em plantio direto. 2.ed. Passo Fundo: Embrapa Trigo, 2003. p.11-132.

SANTOS, H.P. dos; TOMM, G.O.; SPERA, S.T.; ÁVILA, A. Efeito de práticas culturais na conversão e balanço energético. Bragantia, v.66, p.299-306, 2007.

SAS INSTITUTE. SAS system for Microsoft Windows. Version 8.2. Cary: SAS Institute, 2003.

SCOTT, W.O.; KRUMMEL, J. Energy used in producing soybean. In: PIMENTEL, D. (Ed.). Handbook of energy utilization in agriculture. Boca Raton: CRC, 1980. p.117-121.

STRECK, E.V.; KÄMPF, N.; DALMOLIN, R.S.D.; KLAMT, E.; NASCIMENTO, P.C. do; SCHNEIDER, P.; GIASSON, E.; PINTO, L.F.S. Solos do Rio Grande do Sul. 2.ed. rev. ampl. Porto Alegre: Emater, 2008. 222p.

WEAVER, S.H. Energy use in the production of oats. In: PIMENTEL, D. (Ed.). Handbook of energy utilization in agriculture. Boca Raton: CRC, 1980. p.85-92.

Recebido em 26 de abril de 2010 e aprovado em 19 de agosto de 2011 